\title{
Du sollst keine anderen Götter neben dir haben
}

Erhard Taverna

erhard.taverna@saez.ch
Der Autor rät den Lesern, «nicht nach der «wahren Wahrheit zu suchen, sondern sich zu fragen, ob die von ihnen geliebte Wahrheit nützlich und wohltuend ist und niemandem schadet.» Das moralische Gesetz in mir, hat Immanuel Kant das benannt oder: «Handle so, dass du wollen kannst, deine Maxime solle ein allgemeines Gesetz werden.» In dieser Tradition des Königsberger Philosophen kann man PD Dr. med. Jakob Bösch einen Aufklärer nennen, der den Leser aus der selbstverschuldeten Unmündigkeit herausführen will. Ironisch und provokativ beschreibt er den «Erleuchtungsstress», dem sich die meisten Zeitgenossen aussetzen, um dabei regelmässig sich selber und ihre Mitmenschen zu überfordern.

Der ehemalige Chefarzt der Externen Psychiatrischen Dienste Baselland führt durch einen Parcours von zwölf kurzen Kapiteln, deren Titel programmatisch einen atheistischen Weg skizzieren. Es sind Stationen, die neugierig machen, etwa «Abschied vom Allmächtigen» oder «Erleuchtet bist du schon» oder «Versöhne dich mit Hitler» bis «Gib dem Zufall eine Chance» oder «Ehrliche Lügner». Jakob Bösch, ein regelmässiger Teilnehmer an Psi-Tagungen und ähnlichen Veranstaltungen, überlässt es dem Urteil des Leserpublikums, ob es seine privaten parapsychologischen Überzeugungen teilen mag oder nicht. Dass er diesen Glauben an paranormale Fähigkeiten wie Hellsichtigkeit oder an Engel, Geistwesen und Verstorbene relativiert, macht sein Anliegen noch glaubwürdiger. Menschliche Vernunft und Liebe zu den Mitmenschen sollen unser Verhalten und Urteilen steuern, neben dieser göttlichen Liebe in unserem Herzen sollen keine anderen Götter Platz haben. Das ist die Kernbotschaft des Buches, und sie wird kämpferisch, kenntnisreich und ehrlich vorgetragen, auch unter Nennung der eigenen biographischen Wege und Umwege. Manches erscheint vielleicht auch plakativ, etwa

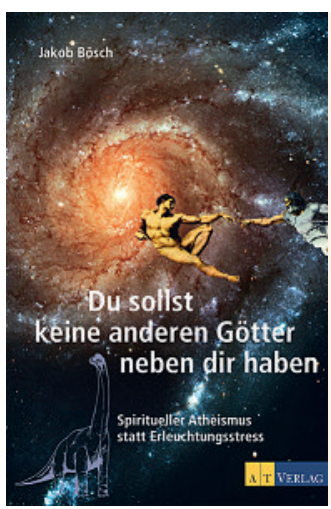

Jakob Bösch

Du sollst keine anderen Götter neben dir haben.

Spiritueller Atheismus statt Erleuchtungsstress. Aarau: AT Verlag; 2010 143 Seiten. $27.90 \mathrm{CHF}$ ISBN 978-3-038-00520-9 das Vertrauen in die Spiritualität der Naturwissenschaften, den Segen des Geldes oder die Verheissungen der Kernkraft und der Gentechnik.

Manchmal ist es schwierig, dem Zick-Zack-Kurs des Autors durch die Welt der Esoterik zu folgen, weil nicht immer klar wird, wo er sich da positioniert. «Haben sie immer einen Mix an Glaubenskonzepten zur Verfügung, die Sie nach Bedarf unterschiedlich akzentuieren können» lautet eine seiner Empfehlungen. Dieses strikt pragmatische Vorgehen macht je nach Standpunkt die Schwäche oder die Stärke dieses Buches aus. Jakob Bösch wird sich mit seinem Werk zwischen viele Stühle setzen. Seine Kritik des positiven Denkens oder der Fürbitte-Euphorie läuft gegen den Trend. Den einen werden seine Ratschläge zu beliebig sein, andere werden sich an der Lichtmetaphorik stören, wieder andere an der Bruderschaft von Hitler und Moses. Das medizinische Establishment wird er mit seiner Wertung der Methoden und Erfolge philippinischer Geistheiler frustrieren, der eigenen Fangemeinde mag er kein Guru sein.

Wer mit pseudoethischen, religiös verbrämten Vorgaben Standespolitik betreibt, oder unter der vatikanähnlichen Bundeshauskuppel mit ihrem Goldkreuz die Sterbehilfe bekämpft, muss sich Einseitigkeit und Gefühlskälte vorwerfen lassen. Glaubensfreiheit bedeutet nicht einfach, einen fast absoluten Respekt gegenüber Glaubensgemeinschaften nachzuleben. Wie André Comte-Sponville, der auch für eine Spiritualität ohne Gott plädiert, schränkt Jakob Bösch das Recht auf eine freie Meinungsäusserung ein. Denn diese gelte nur, «... solange keine Indoktrination und Androhung von irgendeiner Form von Gewalt und Repression im Diesseits wie im Jenseits damit verbunden ist. Das Erzeugen von Angst vor Fegefeuer, vor Hölle oder irdischer Strafe Gottes in Form von Krankheit oder Katastrophen wird aber immer noch weitgehend toleriert.» Drohungen und Beschimpfungen als Briefe oder E-Mails seien Offizialdelikte und gehörten in die gleiche Kategorie. Im letzten Kapitel «Gottes Söhne», das der Autor dem Andenken seines Vater widmet, befasst er sich folgerichtig mit der Judasfigur des neues Testaments. In dessen Verrat erkennt er die gelungene Dramaturgie eines Herrscherplans. Für diesen Judas hat schon der Theologe Kurt Marti, auch er ein Aussenseiter, das Gedicht «Abendland» geschrieben:

«ach was war - dein EINER Verrat - gegen die VIELEN - der christen der kirchen - die dich verfluchen? // ich denke dir nach - und deiner - tödlichen trauer - die uns beschämt.» 